\title{
A Brief Analysis on the Development and Inheritance of SuZuo Ming-style Furniture in Late Ming Dynasty
}

\author{
Lu Ting $^{1,}$ a , Dong Wenying ${ }^{1,2, b}$, Wen Zhengjun ${ }^{1, c}$ \\ ${ }^{1}$ Sichuan agricultural University, College of Forest, Chengdu 611134, Sichuan, China \\ ${ }^{2}$ Central South University of Forestry and Technology, Changsha 410000, Hunan, China \\ a1291112993@qq.com, ${ }^{b} 10775660 @ q q . c o m,{ }^{c} 11517111 @ q q . c o m$
}

\begin{abstract}
Key words: Late Ming Dynasty, SuZuo Ming-style furniture, Modern Chinese-style furniture, Inheritance

Abstract: In late Ming Dynasty, SuZuo Ming-style furniture had culminated in the history of furniture in China, which integrated technology and art of traditional furniture with diversified forms and various features. Based on narrating the design ideas and characteristics of SuZuo Ming-style furniture in late Ming Dynasty, it summarizes how SuZuo Ming-style furniture has been developing and inheriting by modern designers, so as to provide some references for people to understand and study SuZuo Ming-style furniture in late Ming Dynasty more conveniently.
\end{abstract}

Historically, the furniture, which is produced around southern region centered on Suzhou, Hangzhou, Nanjing and Wuxi, is collectively known as "SuZuo",[1]. The traditional SuZuo can be divided into framework and joinery work. Joinery work includes furniture, appliances, doors and windows; furniture of which occupies a very important position of all. As a result of effects generated from the political, economic, cultural and other factors, Ming-style furniture in late Ming Dynasty was designed and manufactured by literati and skilled craftsmen who made it rich in elegance with unique rhymes and exquisite craft. And SuZuo Ming-style furniture, which was abounding in Suzhou, is praised as the typical representative of Ming-style furniture. It is praised all over the world for concise form, exquisite proportion and elegant lines.

\section{The Design Concept of SuZuo Ming-style Furniture Bred}

The economy reached an unprecedented pomp in late Ming Dynasty as the imperial court declaring to abolish the ban on maritime trade and great progress of the handicraft industry and agriculture. Furthermore, the change of humanistic feelings also promoted the germination of the design concept of Su Zuo Ming-style furniture. People's demand for spiritual enjoyment had been continuously improved, which haddriven the commercialization of urban cultural products, and finally formed the prevalence of consumption, enjoyment and extravagance in late Ming Dynasty, so as to propel the integration of vulgar culture and subculture. Under the social background at that time, great changes had been taken placed in the mentality of literati, mainly manifested in aesthetic temperament and values, thereafter the cooperative learning of literati and craftsmen promoted the development of $\mathrm{Su}$ Zuo Ming-style furniture in late Ming Dynasty.

\section{The Influence of Literati Aesthetic Temperament and Values}

In late Ming Dynasty, a large number of literati praised things to express their lonely state due to their unrecognized talent. Indulged in the design and construction of garden and furniture display, literati linked their own values and aesthetic temperament, and integrated them into the design, which made construction of garden and furniture display show a unique temperament of literati, in addition to the aesthetic sense of modeling.

Attached importance to humanity and naturally inspired. During the late Ming dynasty, Yang Ming's Mind Theory was in vogue, and created a theoretical basis for satisfying the desire of individuality and pursuit of individual needs, which appeared to be in accordance with human nature. 
Besides, the literati also respected the free thought of Zhuang $\mathrm{Zi}$ and advocated the combination of humanity and nature. SuZuo Ming-style furniture also pursuits nature, the most significant performance was the preservation of natural attributes of materials. In Ming Dynasty, the lacquer decoration process had been quite mature. But SuZuo Ming-style furniture was mostly used varnish treatment after waxing; the wax was baked into the wood. It was more difficult in the production, however it could fully retain the natural wood texture and color characteristic ${ }^{[2]}$.

Respect harmony and balance while advocating elegance and avoiding vulgarity. Confucius's "Golden mean" is regarded as the highest form of morality by the Confucian school. "Mean" and "harmony" requires the harmony between individuals and society, so as to man and nature. The theme of "respecting harmony and balance" is to achieve the beauty of harmony as a whole by fusing the aesthetic sense in morality and etiquette and other diversified elements. Elegance is the aesthetic character of ancient scholars. And they had poured this kind of literati's inherent feelings into the design of SuZuo Ming-style furniture intentionally or unconsciously.

\section{The Influence of Literati and Craftsmen Collaboration}

Since emperor Jiajing of Ming Dynasty, the adjustment of the artisan service system allowed people to liberate freedom of the individual, which greatly enhanced the creative enthusiasm of craftsmen. At the same time, the contact between literati and craftsmen gradually turned close, it helped the literati to increase practical skills and experience by understanding creative insights and production experience of folk artists, also it cultivated the artistic ability of craftsmen to elevate the artistic aesthetic level of themselves. The famous man, He Wei-ran, once said " the skillful technology of SuZuo Ming-style furniture is enough to immortality".

\section{The characteristics of SuZuo Ming-style Furniture in Late Ming dynasty}

As classic furniture in the history of China and even the world, SuZuo Ming-style furniture has been used so far with reasonable material selection, distinctive modeling style, unique structure, exquisite structure stitching and beautiful decoration which make furniture an entity and a culture.

AboutMaterials. Wood is still the highest produced material of Ming-style furniture, with wood as the main body of Ming-style furniture; Ming-style furniture has experienced improvement and innovation of countless generations of craftsmen to form the unique oriental style "wood culture". In late Ming Dynasty, SuZuo Ming-style furniture mainly used Rosewood, Africa enbony, Scented wood and so on, besides them, for instance, beech was also the main material for making SuZuo Ming-style furniture, it was abundant in Jiangnan with natural and beautiful texture and tone that fully showed the natural beauty of hardwood. Historically, in Suzhou, it was especially hard to obtain good materials for underdeveloped traffic in ancient times, so the craftsmen carefully counted and used the wood as gold. In this way, the craftsmen made up for the defects of the raw materials with exquisite workmanship, to be specific, the large appliances often used package - encrusted technique, which took the miscellaneous wood as the bone with the high quality hardwood as the panel, the small ones were more carefully considered with pieces pieced together.

SuZuo Ming-style furniture not only used wood, also put forward that the furniture such as bed, bookcase could use bamboo as the most "elegant" material, according to the record in "Treatise on Superfluous Thing" that "a fine bed made of cypress cut like a bamboo." The bamboo material adds a rich and rustic flavor of regional culture to Su Zuo Ming-style furniture and also conveys the richness of life in Jiangnan.

About Modeling. SuZuo Ming-style furniture makes the use of the various, simple and fluent lines.It not only has the structural line of an integral frame outline, such as Chair Leg, Gooseneck Front Posts, also it has the decorative lines of the partition space such as Chair Back, Detail Pillar-shaped Strut. Besides there are straight lines, such as Stretcher, and soft and gentle curves likethe top beam of the furniture Top Rail. These straight lines and curves have created the strong and majestic beauty of SuZuo Ming-style furniture, the graceful beauty and the soft, smooth and fluent beauty as well. 
Differences in concave-convex, thicknesses, length of the line that makes modeling of SuZuo Ming-style furniture to be different between the same and the static brings exuberant vitality for modeling.For example, the Arm chair With Four Protruding Ends,curve processing is performed on many components, the middle of Top Rail is cut to get a certain slope with the two sides firstly slightly dropping, and then slightly stirring to the two ends (Figure1, Armchair With Four Protruding Ends of SuZuo Ming-style furniture). For another example, Folding Chair of SuZuo Ming-style furniture, the curves and lines match well, the curve of the round back is soft and comfortable with fastidious manufacture,seems that the crossed Chair Foot and Pedals are more in line with the needs of people(Figure2, Folding Chair of SuZuo Ming-style furniture).
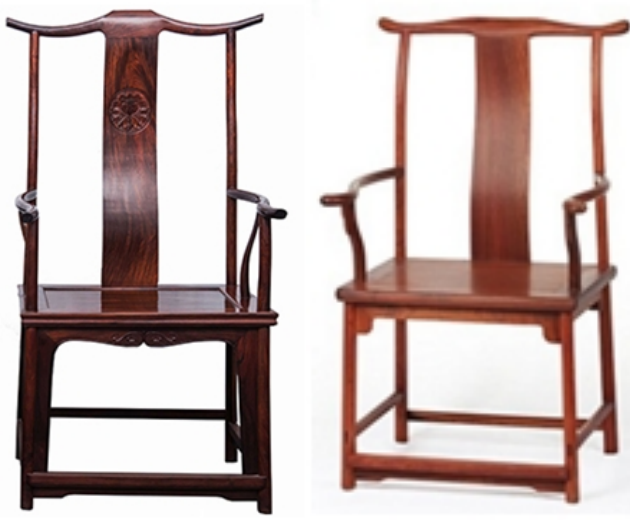

Fig1. Arm chair With Four Protruding Ends of SuZuo Ming-style furniture
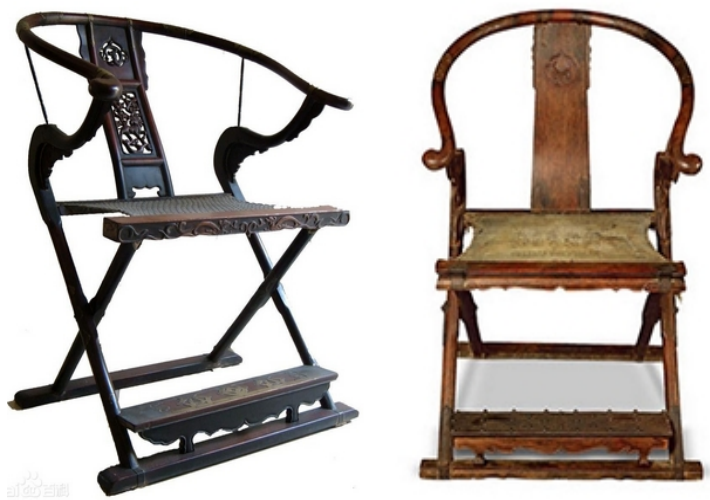

Fig2. Folding Chair of SuZuo Ming-style furniture

SuZuo Ming-style furniture realizes the function of the chair by using the concept of area, with the combination of square surface and curve surface, the shape of the chair is better to meet people's needs and achieve the most reasonable and most comfortable use effect. For example, the Top Rail surface and the Backrest usually are together to be made of "S"- shaped surfaces to support the neck and head of the human body, while which adjusts the rigidity of the square surface.

Abut structure. SuZuo Ming-style furniture is praised for its tenon structure, and its connection is exquisite and skillful, which has reached a high level.Tenon structure with a male and a female in tenon is changeful in SuZuo furniture, there are as many as thirty-three kinds of the existing recovery and innovation in Mingshi Pavilion, many of which are not existed in other regions and schools ${ }^{[3-4]}$. Craftsmen could design and manufacture sophisticated and precise mortise and tenon structure according to actual needs, they are tight enough, as if it is inartificial. Besides, the use of mortise and tenon structure maximize saving the material furthest, and embodies the economy of furniture design. Taking round-backed armchair of the SuZuo Ming-style furniture as an example, it is composed of seven sections of wood by the connection of Dowel Tenon, which greatly saves the material and keeps the beauty of the furniture.

About Decoration. The SuZuo Ming-style furniture is not painstakingly decorated with elaborate carvings or other decorations, but rather by the use of selective structural components for decoration, therefore, the furniture model not only plays a stabilizing role, but also takes the aesthetic effect into account. In short, from the practical and aesthetic point of view, it embodies the proper design of SuZuo Ming-style furniture, and lays a solid foundation and opens up a new road for the development of furniture in the future.

\section{The Modern Civilizations and Spirit of Times Promotes the Development and Inheritance of SuZuo Ming-style Furniture}

SuZuo Ming-style furniture has become the past. At the same time, there is a big difference on life needs and aesthetic requirements between modern people and the ancients. In a new era,we should pay more attention to the spiritual inheritance of SuZuo Ming-style furniture, as the cultural fusion is an 
irreversible historical trip, it requires designers to bring forth the new through inheriting the cultural classics and regional culture on the basis of the old and new with an integration of Chinese and western.

Modern Chinese-style furniture has the shadow of SuZuo Ming-style furniture, which is enriched in shape, diversified in decoration and concise in parts. Meanwhile, the combinations of point-line-area design elements greatly meet the needs of modern life. But compared with SuZuo Ming-style furniture, it is far from enough. The designer need to make an effort on extraction, transformation, innovation and application of the connotation of traditional culture with modern aesthetic concept, and make it rich in characteristics of the times or expressing a design concept, it is the recreation and redesign of traditional styling. For example, the backrest of round-backed arm chair among SuZuo Ming-style furniture, it combined complicated arc and dowel tenon which may be very classic tenon joint among the furniture culture, but in terms of modern mass production, it exists with low production efficiency and high price, so It is not suitable for the development and the demand of modern furniture industry. Therefore, while redesigning SuZuo Ming-style furniture, designers should not only meet the needs of modern people's favorite, but also consider the realization of the economic efficiency of enterprises.

SuZuo Ming-style furniture is designed mainly based on unique and fantastic Chinese elements, focusing on the understanding and application of "harmony between man and nature, harmony between Yin and Yang", though each chair type of furniture had been crafted, but decorative patterns were too complicated. Currently, designers can summarize and induce the constituent elements of decorative components of SuZuo Ming-style furniture, with data processing through deformation, combination of cultural elements, exaggeration, generalization and other techniques, and seize its charm, catch the simple, finally highlight the main theme and cultural connotation. Certainly, designers can also expand decorative elements of the traditional development with joining modern auspicious elements, or transplant decorative elements of the traditional development by Chinese shadow plays, Chinese paper-cut and other forms of transplantation. Accessories of SuZuo Ming-style furniture generally are used metal material to decorate. Besides that, the designer can manufacture and install modern Chinese chairs and furniture by the combination of metal and non-metallic materials according to the tastes of modern consumers.

\section{Conclusions}

As for SuZuo Ming-style furniture, its development should be understood and respected, while being learned to extract and summarize the designing essence, including shape, structure, decoration and other aspects. When it comes to its inheritance, it should not entirely be copied, but inherited selectively according to the characteristics of the times. The designers have to put emphasis on coordination of the modern life and pay equal attention to both practical and aesthetic characteristics. Nowadays, there are many ways to innovate SuZuo Ming-style furniture. However, we must go back to the essence of the source, so that innovation can be vigorous to provide a steady flow of power for development of the furniture market in the future.

\section{Acknowledgements}

This work was financially supported by the major project of humanities and social sciences of education department of Sichuan province (16SA0006), the Key Laboratory of Wood Industry and Furniture Engineering of Sichuan provincial education department, the project of Undergraduate Scientific Research Interest of Sichuan Agricultural University, the phased objectives of Interior design philosophy course team of Sichuan Agricultural University.

\section{References}

[1] Qian Feng. Analysis of the Cause of Ming-Style furniture Prosperity, Exploration of Art, Vol. 25, 04 (2011), p.130-131. 
[2] Zhang Qian. The study on Relation between Garden Building and Furniture of Soochow in Late-Ming Dynasty, Central South University of Forestry Technology (2016.6).

[3] Zhang Dishu, Traditional Features of Ming-style Furniture, Forest products industry, Vol.26, 05(1999), p.13-17.

[4] Shi Zhongming, Shi Zhiye, Cultural Inheritance and Innovation of Su Zuo, Shanghai Arts \& Crafts, Vol.10, 03(2014), p.114-115. 